\begin{tabular}{ll|l}
\cline { 2 - 3 } & \multicolumn{2}{l}{ Intervent Neurol 2014;3:85-100 } \\
\cline { 2 - 3 } & $\begin{array}{l}\text { DOI: 10.1159/000371453 2015 S. Karger AG, Basel } \\
\text { Published onlıne: January 21, } 2015\end{array}$ & $\begin{array}{l}\text { (c) } \\
\text { 1664-9737/15/0032-0085 } \$ 39.50 / 0 \\
\text { www.karger.com/ine }\end{array}$ \\
\hline
\end{tabular}

\title{
Implementation of Intraoperative Neurophysiological Monitoring during Endovascular Procedures in the Central Nervous System
}

\author{
Alicia Martinez Piñeiro ${ }^{a}$ Carles Cubells $^{b} \quad$ Pablo Garcia $^{a} \quad$ Carlos Castaño $^{a}$ \\ Antonio Dávalos ${ }^{a}$ Jaume Coll-Canti ${ }^{a}$ \\ a Service of Neurology and Section of Interventional Neuroradiology, Department of \\ Neurosciences, Hospital Germans Trias i Pujol, Universitat Autònoma de Barcelona, and \\ ${ }^{b}$ Department of Anesthesiology, Germans Trias i Pujol University Hospital, Barcelona, Spain
}

\begin{abstract}
Key Words
Central nervous system, vascular pathology - Endovascular treatment - Evoked potentials .

Intraoperative neurophysiological monitoring · Provocative tests
\end{abstract}

\begin{abstract}
Background and Objective: Intraoperative monitoring (IOM) has been used in different surgical disciplines since the 1980s. Nonetheless, regular routine use of IOM in interventional neuroradiology units has only been reported in a few centers. The aim of this study is to report our experience, 1 year after deciding to implement standardized IOM during endovascular treatment of vascular abnormalities of the central nervous system. Methods: Basic recordings included somatosensory-evoked potentials (SEPs) and motor-evoked potentials (MEPs). Corticobulbar motor-evoked potentials and flash-visual-evoked potentials were also recorded depending on the topography of the lesion. Intra-arterial provocative tests (PTs) with amobarbital and lidocaine were also performed. All patients except 1 were under total intravenous anesthesia. Clinical outcome was assessed prospectively and correlated with IOM events. Results: Twelve patients and 15 procedures were monitored during the inclusion period. Significant IOM events were detected during 3 of the 15 procedures (20\%). We observed temporary MEP changes in 2 cases which resolved after interruption of the embolization or application of corrective measures, leaving no postoperative neurological deficits. In 1 case, persistent SEP and MEP deterioration was detected secondary to a frontal hematoma, resulting in mild sensory-motor deficit in the right upper extremity after the procedure. Overall, 12 PTs (4 spinal cord and 8 brain abnormalities) were performed using lidocaine and sodium
\end{abstract}


Martinez Piñeiro et al.: Implementation of Intraoperative Neurophysiological

amytal injections. One positive result occurred after the injection of lidocaine. No false negatives were detected. Conclusions: IOM may provide continuous real-time data about the functional status of eloquent areas and pathways of the central nervous system in patients under general anesthesia. It therefore allows us to detect early neurological damage in time to perform specific actions that may prevent irreversible neurological deficits.

(C) 2015 S. Karger AG, Basel

\section{Introduction}

Over the last 2 decades, interventional neuroradiology has established itself as a new therapeutic approach for vascular abnormalities of the central nervous system, including aneurysms, arteriovenous malformations (AVMs), dural fistulas, vessel stenosis, and hypervascular tumors. Its indications include preoperative treatments aimed at decreasing vascularity, palliative treatments for incurable diseases, and curative therapy [1]. Most of the techniques employed are potentially dangerous because they may compromise cerebral or spinal cord blood flow, resulting in ischemic stroke (the use of embolization material) or hemorrhagic stroke (vessel dissection due to stent placement). Most of these procedures are performed under general anesthesia to keep the patient comfortable and immobilized in order to obtain high-resolution images. In this situation, intraoperative neurophysiological monitoring (IOM) is the only way to obtain information about the functional status of central nervous system pathways. Another alternative would be to perform a wake-up test, but this technique has important limitations. First, it cannot provide continuous information about the functional integrity of motor and sensory pathways, and injuries are not always related to risky maneuvers. Second, it requires a high degree of patient cooperation in order to deliver reliable and confident results.

The primary goal of IOM is to detect neurological damage early, when it may still be reversible, in order to prevent the development of permanent neurological deficits. Another important and specific contribution of IOM during endovascular procedures in the brain and spinal cord is the use of provocative tests (PTs). These intra-arterial injections of short-acting barbiturates or lidocaine allow us to determine whether one vessel feeds the vascular malformation or eloquent areas of the central nervous system. IOM, in particular somatosensoryevoked potential (SEP) monitoring, has been practiced not only in neurosurgery and orthopedics but also in interventional neuroradiology since the 1980s [2, 3]. Initially, several reports cited the unreliability of SEPs for detecting motor pathway injuries, which cast doubt on this practice $[4,5]$. Nonetheless, developments in the method for assessing motor-evoked potentials (MEPs) in patients under general anesthesia [6, 7] have contributed critically to reducing this limitation, thereby lending IOM more credibility as a means of detecting intraoperative motor and sensory deficits.

Despite these advances, the standardized use of the technique in daily clinical practice has only been reported in a few interventional neuroradiology units [8]. Specially, reports on the use of PTs and multimodality neurophysiological monitoring [SEPs, muscle MEPs, corticobulbar MEPs (CoMEPs) and flash-visual-evoked potentials (VEPs)] during the embolization of brain AVMs in eloquent areas are more anecdotal than those related to procedures in spinal cord. Paulsen et al. [9] used PTs with amobarbital in 17 awake patients together with neurological examination and SEP monitoring during the embolization of rolandic AVMs. Sala et al. [10] reported 21 endovascular procedures in 11 patients with brain AVMs in eloquent sensory-motor areas. They performed 58 PTs using only lidocaine. Currently, after an exhaustive review of the literature, there are no other reports on the combined use of SEPs, muscle MEPs, and PTs during the embolization for cortical AVMs under general anesthesia. 
Martinez Piñeiro et al.: Implementation of Intraoperative Neurophysiological

In the present study, we describe our experience, 1 year after deciding to implement standardized IOM during endovascular treatment for central nervous system abnormalities. Most of the patients included (8/12) presented cortical lesions. Thus, our findings could contribute to the interpretation of muscle MEP alarm criteria, which are different from those used during spinal cord surgeries, and to identify the correlates between intraoperative neurophysiological events and patient clinical outcome. Regarding the intraoperative neurophysiological modalities used, we report the implementation of flash-VEP IOM during the embolization of an occipital AVM. To our knowledge, there have been reports on its use during surgical but not endovascular procedures (Sasaki et al. [11]).

\section{Patients and Methods}

Between November 2011 and January 2013, we recruited patients who underwent elective endovascular treatment for vascular abnormalities involving the central nervous system, including both spinal cord and brain lesions.

\section{Intraoperative Neurophysiological Methods}

All recordings were taken using a 10-channel Medelec Synergy system (Vyasis Healthcare) together with an external stimulator (Digitimer multipulse cortical stimulator, D185). The basic data recorded in most procedures included measurements of SEP and muscle MEP. However, a multimodal and individualized approach is strongly recommended for assessing the functional status of central nervous system areas and pathways which may be at risk during the procedure. Thus, some cases required different techniques, such as recording CoMEPs and VEPs (table 1).

Somatosensory-Evoked Potentials

SEPs were recorded according to conventional methods [12]. SEPs were elicited by electrical stimulation of the right and left median nerves at the wrist and the left posterior tibial nerves at the ankle using needle electrodes [Ambu Neuroline Subdermal, $12 \times 0.4 \mathrm{~mm}(0.5$ inch $\times 27 \mathrm{G}) 200 \mathrm{~cm}$ ]. The following parameters were used for stimulation: an intensity of $40 \mathrm{~mA}$, duration of $0.2 \mathrm{~ms}$, and repetition rate of $5 \mathrm{~Hz}$. Transcranial recordings were performed using corkscrew needle electrodes inserted subcutaneously in the scalp (Technomed Europe, $0.6 \mathrm{~mm}, 23 \mathrm{G}, 120 \mathrm{~cm}$ ). The response to stimulation was recorded at C3'-C4' $/ \mathrm{Cz}^{\prime}$ for the median nerves and at $\mathrm{Cz}^{\prime} / \mathrm{Fz}$ for the posterior tibial nerves, according to the International 10/20 system for EEG electrode placement. We chose a high bandpass filter of $3 \mathrm{kHz}$ and low bandpass filters of 3 and $10 \mathrm{~Hz}$ for the median and posterior tibial nerves, respectively. In cases of vascular pathology, it is preferable to monitor both contralateral and ipsilateral SEPs in order to distinguish between events related to the procedure and those secondary to hemodynamic or systemic changes. Alternatively, it may be extremely useful to record SEPS from a suboccipital electrode (CV2). A decrease in SEP amplitude exceeding 50\% or a latency increase of $10 \%$ have been considered alarm criteria for vascular abnormalities in both spinal cord and brain.

Motor-Evoked Potentials

MEPs were elicited by transcranial electrical stimulation (TES) of the motor cortex using corkscrew needle electrodes. Short pulse trains of 5-7 square-wave stimuli, with a duration of $0.5 \mathrm{~ms}$, interstimulus intervals of $4 \mathrm{~ms}$, and a constant voltage intensity of up to $300 \mathrm{~V}$, were applied at a repetition rate of 1-2 $\mathrm{Hz}$ from C1/C2 or C3/C4, according to the International 10/20 system for EEG electrode placement [7]. The C3/ C4 montage is more efficient, partly because less current passes through the scalp between the widely spaced electrodes [13]. However, it can also promote deeper current penetration, which may increase the risk of failing to detect cerebral motor compromise rostral to a deep activation site [14]. The most focal montage of stimulating electrodes to elicit muscle MEPs from the upper muscles is achieved with $\mathrm{C} 3-\mathrm{C} 4 / \mathrm{Cz}$ [15]. This electrode placement corresponds to the projection of the cortical motor hand area at C3 or C4, respectively. This is in accordance with the results from direct cortical stimulation demonstrating the homunculus [16] as well as results using bipolar TES [17].

The most focal stimulating electrode montage to elicit motor responses from the lower extremity muscles can be achieved with the montage at $\mathrm{Cz} / \mathrm{Cz}+6 \mathrm{~cm}$. However, the latter turns out to have a higher stimulation threshold and is, therefore, successful in only $68 \%$ of the patients. TES of the motor cortex to 
Martinez Piñeiro et al.: Implementation of Intraoperative Neurophysiological

Monitoring during Endovascular Procedures in the Central Nervous System

Table 1. Characteristics of the patients, type of pathology and endovascular procedure, IOM methodologies, events, and clinical outcome

\begin{tabular}{|c|c|c|c|c|c|c|c|}
\hline $\begin{array}{l}\mathrm{Pa}- \\
\text { tient } \\
\text { No. }\end{array}$ & $\begin{array}{l}\text { Gen- } \\
\text { der }\end{array}$ & $\begin{array}{l}\text { Age, } \\
\text { years }\end{array}$ & Pathology & $\begin{array}{l}\text { Endovascular } \\
\text { procedure/ } \\
\text { material }\end{array}$ & $\begin{array}{l}\text { IOM } \\
\text { methodology }\end{array}$ & IOM events & $\begin{array}{l}\text { Outcome } \\
\text { ( } 48 \mathrm{~h} \text { after endovascular } \\
\text { procedure) }\end{array}$ \\
\hline 1 & $\mathrm{~F}$ & 66 & $\begin{array}{l}\text { Spinal cord AVM } \\
\text { (C1-C2) } \\
\text { Sulcal artery } \\
\text { pseudoaneurysm }\end{array}$ & $\begin{array}{l}\text { Embolization/ } \\
\text { histoacryl }\end{array}$ & $\begin{array}{l}\text { SEPs } \\
\text { MEPs } \\
\text { PT (L) - }\end{array}$ & None & No neurological deficits \\
\hline 2 & M & 69 & $\begin{array}{l}\text { Vertebral hemangioma } \\
\text { (T5) }\end{array}$ & $\begin{array}{l}\text { Embolization/ } \\
\text { particles }\end{array}$ & SEPs (awake) & None & No neurological deficits \\
\hline \multirow[t]{2}{*}{3} & $\mathrm{~F}$ & 22 & $\begin{array}{l}\text { Spinal cord AVM } \\
\text { (C6-C7) }\end{array}$ & $\begin{array}{l}\text { Embolization/ } \\
\text { Onyx }\end{array}$ & $\begin{array}{l}\text { SEPs } \\
\text { MEPs } \\
\text { PT (L) - }\end{array}$ & None & No neurological deficits \\
\hline & & & & $\begin{array}{l}\text { Embolization/ } \\
\text { Onyx }\end{array}$ & $\begin{array}{l}\text { SEPs+MEPs } \\
\text { PT }(L, 2 \times)-\end{array}$ & $\begin{array}{l}\downarrow 90 \% \text { MEP amplitude, left } \\
\text { APB and biceps, right APB } \\
\text { and bilateral TA } \\
\text { No changes in bilateral } \\
\text { median and tibial SEPs }\end{array}$ & No neurological deficits \\
\hline 4 & M & 50 & MCA aneurysm (right) & $\begin{array}{l}\text { Embolization } \\
\text { and remodeling/ } \\
\text { coils }\end{array}$ & $\begin{array}{l}\text { SEPs } \\
\text { MEPs } \\
\text { PT (L) + }\end{array}$ & None & No neurological deficits \\
\hline 5 & M & 74 & ICA aneurysm (right) & $\begin{array}{l}\text { Occlusion test/ } \\
\text { stenting }\end{array}$ & $\begin{array}{l}\text { SEPs } \\
\text { MEPs }\end{array}$ & None & No new neurological deficits \\
\hline 6 & M & 43 & MCA aneurysm (right) & $\begin{array}{l}\text { Embolization/ } \\
\text { coils }\end{array}$ & $\begin{array}{l}\text { SEPs+MEPs } \\
\text { CoMEPs(VII) }\end{array}$ & None & No neurological deficits \\
\hline 7 & M & 69 & $\begin{array}{l}\text { Basilar artery (trunk) } \\
\text { aneurysm }\end{array}$ & $\begin{array}{l}\text { Stenting and } \\
\text { embolization/ } \\
\text { coils }\end{array}$ & $\begin{array}{l}\text { SEPs+MEPs } \\
\text { CoMEPs }\end{array}$ & None & No neurological deficits \\
\hline 8 & M & 60 & $\begin{array}{l}\text { Fronto-opercular } \\
\text { AVM (left) }\end{array}$ & $\begin{array}{l}\text { Embolization/ } \\
\text { Onyx }\end{array}$ & $\begin{array}{l}\text { SEPs } \\
\text { MEPs } \\
\text { CoMEPs } \\
(\text { CTHY)* } \\
\text { PT }(L+A, 2 \times)-\end{array}$ & $\begin{array}{l}\downarrow>90 \% \text { MEP amplitude, } \\
\text { extensor digitorum communi } \\
\text { (right) } \\
\downarrow 50 \% \text { SEP amplitude, right } \\
\text { median nerve }\end{array}$ & $\begin{array}{l}\text { Fronto-temporal hematoma } \\
\text { Motor aphasia and moderate } \\
\text { right hemiparesia and } \\
\text { hemihypoesthesia }\end{array}$ \\
\hline \multirow[t]{3}{*}{9} & M & 38 & $\begin{array}{l}\text { Frontal AVM } \\
\text { (right) }\end{array}$ & $\begin{array}{l}\text { Embolization/ } \\
\text { Onyx }\end{array}$ & $\begin{array}{l}\text { SEPs } \\
\text { MEPs }\end{array}$ & $\begin{array}{l}\downarrow 80 \% \text { MEP amplitude. left } \\
\text { AH } \\
\text { No changes in bilateral } \\
\text { median and tibial SEPs }\end{array}$ & No neurological deficits \\
\hline & & & & $\begin{array}{l}\text { Embolization/ } \\
\text { Onyx }\end{array}$ & $\begin{array}{l}\text { SEPs } \\
\text { MEPs } \\
\text { PT (L) - }\end{array}$ & None & No neurological deficits \\
\hline & & & & $\begin{array}{l}\text { Embolization/ } \\
\text { Onyx }\end{array}$ & SEPs+MEPs & None & $\begin{array}{l}\text { Repeated focal motor } \\
\text { seizures with Todd's paresis: } \\
\text { left lower limb plegia after } \\
23 \text { h of orotracheal intubation } \\
\text { (recovered after } 48 \mathrm{~h} \text { ) }\end{array}$ \\
\hline 10 & M & 41 & Occipital AVM (left) & $\begin{array}{l}\text { Embolization/ } \\
\text { Onyx }\end{array}$ & $\begin{array}{l}\text { Transcranial } \\
\text { VEP }\end{array}$ & None & No neurological deficits \\
\hline 11 & $\mathrm{~F}$ & 42 & $\begin{array}{l}\text { Cerebellar } \\
\text { (vermian) AVM }\end{array}$ & $\begin{array}{l}\text { Embolization/ } \\
\text { Onyx }\end{array}$ & $\begin{array}{l}\text { SEPs+MEPs } \\
\text { CoMEPs (V) } \\
\text { PT }(L)-\end{array}$ & None & No new neurological deficits \\
\hline 12 & M & 51 & Frontal AVM (left) & $\begin{array}{l}\text { Embolization/ } \\
\text { Onyx }\end{array}$ & $\begin{array}{l}\text { SEPs+MEPs } \\
\text { CoMEPs(VII) } \\
\text { PT (L) - } \\
\text { PT (A) - }\end{array}$ & None & No new neurological deficits \\
\hline
\end{tabular}

A = Amobarbital; ICA = internal carotid artery; L = lidocaine; $V=$ trigeminal nerve; VII = facial nerve. $*$ Cricothyroid muscle

elicit muscle MEPs stimulates axons at a subcortical level, and this may increase the risk of false negative results. The higher the current used, the higher this risk becomes [18]. Thus, when muscle MEP monitoring of the upper and lower extremities is needed in cortical lesions, the most desirable montage is one that avoids a subcortical excitation of the corticospinal tract, which may bypass the site of the lesion. Both $\mathrm{C} 3 / \mathrm{C} 4$ and C1/C2 montages elicit arm and leg MEPs with lower intensity thresholds than $\mathrm{C} 3-\mathrm{C} 4 / \mathrm{Cz}$ and $\mathrm{Cz} / \mathrm{Cz}+6 \mathrm{~cm}$ 
Martinez Piñeiro et al.: Implementation of Intraoperative Neurophysiological

Monitoring during Endovascular Procedures in the Central Nervous System

[15]. Montage at C1/C2 is less potent and activates the corticospinal tract less deeply than at C3/C4, probably because more current shunts through the scalp [13]. Furthermore, it induces less movements disturbing supraselective catheterization during AVM embolizations. This is why C1/C2 montage is recommended for brain lesions, whereas C3/C4 montage is the first choice for spinal cord disease.

Muscle responses were recorded by inserting a pair of manually twisted needle electrodes (Ambu Neuroline Subdermal). The basic montage included bilateral recordings from the abductor pollicis brevis (APB) and the tibialis anterior (TA) or abductor hallucis (AH). We also placed additional electrodes depending on the neurological structures at risk, taking recordings from other lower limb muscles in cases of parasagittal AVM or from other upper limb muscles in cases of cervical AVM with multiple radicular feeders. Bandpass filters of 3-5,000 Hz were applied.

Some factors such as variability, anesthetic vulnerability, faded and high sensitivity should be taken into account for MEP interpretation. We can distinguish different types of alarm criteria based on MEP amplitude (disappearance and irreversible or reversible deterioration), MEP threshold elevation, and morphological simplification. Disappearance has been proposed as the main warning criterion for spinal cord monitoring ('all or none' criterion). It is a strong predictor of new weakness, which is however not necessarily severe or permanent [19]. Muscle MEP deterioration (amplitude reduction) may reflect partial cord injury [20]. Most reports present examples of reversible MEP deterioration with no new motor deficits that provide circumstantial evidence for injury prevention. They also contain consistent evidence that muscle MEP deterioration often occurs before and sometimes without SEP changes. This suggests a greater chance for early detection, intervention, and motor deficit prevention. Criteria based on threshold reaching or exceeding a predefined limit above the baseline have been proposed for several types of monitoring. The most developed threshold criterion consists of an elevation of $\geq 100 \mathrm{~V}$, using C3/C4 constant-voltage 0.05 -ms pulses with an interstimulus interval of $2 \mathrm{~ms}$ and propofol/opioid/nitrous oxide anesthesia without neuromuscular blockade [21]. The largest series reported $100 \%$ sensitivity and $99.7 \%$ specificity for early postoperative weakness in neurosurgical spine surgeries [20].

On the basis of current evidence, the following criteria have been followed for vascular spinal cord pathology: (1) muscle MEP disappearance is a major criterion mandating restorative efforts. It is a strong predictor of new weakness although not necessarily severe or permanent and (2) marked muscle MEP amplitude reduction, acute threshold elevation, or morphological simplification could be minor criteria prompting restorative efforts [22].

For vascular brain pathology, the major criteria include disappearance or a consistent amplitude reduction of $>50 \%$ when trial-to-trial variability permits or a consistent reduction below earlier amplitudes when variability exceeds 50\% [23]. Acute threshold elevation might be relevant. No reports have been published in support of morphological criteria.

The reason for different muscle MEP criteria for spinal cord and brain monitoring might be the large size of the cortical and superficial subcortical motor structures, making partial injury and moderate deterioration more likely in the latter. This hypothesis is supported by MRI evidence that superficial lesions generally reduce amplitude whereas deep lesions typically cause disappearance [23].

Corticobulbar Motor-Evoked Potentials

CoMEPs from muscles supplied by cranial nerves were recorded in lesions involving the vertebrobasilar system or which had potentially compromised feeders of facial and motor language cortical areas. CoMEPs from the mentalis and masseter muscles were elicited in cases of basilar artery aneurysm or cerebellar AVM, respectively (table 1). Recent reports have suggested that a long-latency response (LLR) evoked after TES or direct cortical stimulation of the cricothyroid (CTHY) muscle could be a neurophysiological marker for the opercular part of Broca's area [24]. As a result, this CoMEP would allow us to assess the functional integrity of motor speech areas in a patient under general anesthesia. CoMEPs from the CTHY muscle are reliable and reproducible according to a recently published technique [25]. TES was applied from C3 to Cz for left hemispheric stimulation and from C4 to $\mathrm{Cz}$ for right hemispheric stimulation, according to the International 10/20 system for EEG placement. The stimulation parameters were a pulse train of 5 stimuli with a duration of 0.5 $\mathrm{ms}$, each with an interstimulus interval of 2-4 ms, and an intensity of up to $300 \mathrm{~V}$. For recording, we used a twisted pair of needle electrodes (Ambu Neuroline Twisted Pair Subdermal) according to the methods established by Hirano and Ohala [26]. The needles were inserted while the patient was awake, and we used electromyographic feedback during the production of a high-pitched sound to guarantee the correct placement. Electrode impedance was $<4 \mathrm{k} \Omega$. The bandpass filters applied were 3-5,000 Hz. 
Table 2. Summary of the PT results

\begin{tabular}{|c|c|c|c|c|c|c|c|}
\hline \multirow{3}{*}{$\begin{array}{l}\mathrm{Pa}- \\
\text { tient } \\
\text { No. }\end{array}$} & \multicolumn{2}{|l|}{ Pathology } & \multirow[t]{3}{*}{ Vessel } & \multicolumn{4}{|c|}{ PT } \\
\hline & \multirow[t]{2}{*}{ type } & \multirow[t]{2}{*}{ topography } & & \multicolumn{2}{|c|}{ lidocaine } & \multicolumn{2}{|c|}{$\begin{array}{l}\text { sodium } \\
\text { amobarbital }\end{array}$} \\
\hline & & & & + & - & + & - \\
\hline 1 & AVM (C1-C2) & \multirow[t]{2}{*}{ Spinal cord } & Sulcal artery (anterior spinal artery branch) & - & 1 & - & - \\
\hline 3 & AVM (C6-C7) & & Tirobicervicoescapular artery branch & - & 3 & - & - \\
\hline 4 & Right MCA aneurysm & \multirow[t]{5}{*}{ Brain } & Right MCA bifurcation & 1 & - & - & - \\
\hline 8 & Left fronto-opercular AVM & & Left fronto-opercular MCA branch & - & 1 & - & 2 \\
\hline 9 & Right frontal AVM & & Right pericallosal artery branch & - & 1 & - & - \\
\hline 11 & Vermian cerebellar AVM & & Left anterior-superior cerebellar artery & - & 1 & - & - \\
\hline 12 & Left frontal AVM & & Left external carotid artery branch & - & 1 & - & 1 \\
\hline Total & & & & 1 & 8 & - & 3 \\
\hline
\end{tabular}

Transcranial VEPs

Transcranial VEPs were recorded in a case of occipital AVM according to the method recently published by Sasaki et al. [11]. As a stimulating device, we used 8 flashlight diodes embedded in 2 soft silicone disks. The stimulation had a duration of $20 \mathrm{~ms}$ and a frequency of 1-2 Hz. For recording, we used corkscrew needle electrodes inserted in Cz', Oz, 01, 02, A1, and A2, according to the International 10/20 system for EEG placement. We used low and high bandpass filters ( 1.5 and $300 \mathrm{~Hz}$, respectively) and 200 trials were recorded perVEP. The alarm criterion was defined as a decrease in amplitude $>50 \%$ compared to the baseline recording [11].

Provocative Tests

The goal of PTs is to identify the functional eloquence of the territory of a catheterized vessel [27]. Once the tip of a microcatheter had been placed precisely at the point of embolization, we injected 50 mg shortacting barbiturate (sodium amobarbital) or 20-40 mg lidocaine $[8,18]$. Amobarbital blocks neuronal activity, while lidocaine blocks axonal conduction [28]. Thus, lidocaine is the first choice for spinal cord abnormalities, where ascending and descending white matter tracts are mainly at risk. In these cases, PTs with amobarbital are required to determine whether the catheterized vessel feeds motor neuron cell bodies of the anterior horn. Nonetheless, in cerebrovascular abnormalities, PTs with amobarbital and lidocaine must both be performed because white matter as well as gray matter tracts could be at risk. Amobarbital is not available in our country and it has to be specially requested from abroad. This is the reason why it was not available for use during some brain lesion procedures (table 2).

Since anesthesia and hemodynamic fluctuations have a cumulative effect, baseline SEP and MEP recordings were obtained before each PT was performed. Contrast material was injected under fluoroscopic control to determine the optimal force for amobarbital and lidocaine, so as to avoid false positive results generated by a reflux of those substances to distal vessels. After the injections, SEPs and MEPs were tested continuously during the subsequent 5-10 min. A PT with amobarbital and lidocaine was considered positive, if we detected a decrease of $>50 \%$ in SEP amplitude and/or an absence of MEP in spinal cord disease. MEP warning criteria used after a PT in cases of cerebrovascular abnormalities differ from the 'all or none' criteria used in spinal cord lesions [29]. Due to the complexity of brain vasculature, PTs at this level must be interpreted with caution. We considered a decrease of $>50 \%$ in MEP amplitude as an alarm criterion. Mainly in AVM cases, PTs were performed after superselective catheterization of small-caliber feeders. In this situation, pharmacological testing was chosen over balloon test occlusion, because the risk of vessel rupture or dissection was considered higher with the latter.

\section{Anesthesia}

Anesthesia was induced with propofol [target-controlled infusion (TCI) $4 \mu \mathrm{g} / \mathrm{ml}$ ] and remifentanil (TCI $4 \mathrm{ng} / \mathrm{ml}$ or $0.03-0.015 \mathrm{ng} / \mathrm{kg} / \mathrm{min}$ ) and maintained by continuous infusion of propofol (TCI 2-3 mg/ml) and remifentanil (TCI 3-7 ng/ml). No depolarizing muscle relaxants were used throughout the entire procedure; rocuronium was only administered for endotracheal intubation $(0.5 \mathrm{mg} / \mathrm{kg})$. 


\section{Results}

During the study period, we monitored a total of 15 procedures in 12 patients ( 3 women and 9 men with a mean age of 52 years). Most procedures were embolizations (Onyx ${ }^{\circledR}$ and histoacryl), except for 2 cases of stent placement, 1 carotid occlusion test, and 1 remodeling technique prior to embolization of an aneurysm in the right middle cerebral artery (MCA; coils). Three patients presented spinal cord lesions ( 2 cervical AVMs and 1 vertebral hemangioma at T5) and 9 presented cerebrovascular lesions (5 AVMs and 4 aneurysms -1 in the vertebrobasilar territory and the other 3 in the anterior circulation; table 1). We recorded reproducible SEPs and MEPs during all procedures. Observable CoMEPs were also detected in the mentalis muscle (frontal AVM, MCA aneurysm, and basilar artery aneurysm) and the masseter muscle (cerebellar AVM). Stable and reproducible flash-VEPs were recorded during presurgical embolization of a left occipital AVM (table 1). In one case of a dominant hemisphere frontal-opercular AVM that might compromise speech articulation areas, an LLR was obtained from the right CTHY muscle. Nonetheless, the signal was not stable enough throughout the procedure to be monitored.

\section{Provocative Tests}

We carried out a total of 12 PTs, 4 for spinal cord vascular abnormalities and 8 for cerebrovascular abnormalities. Lidocaine was used for all spinal cord lesions; for the brain lesions, lidocaine was used in 5 cases and amobarbital in the other 3 cases. Overall, only 1 positive result was obtained (8.3\%), following a PT with lidocaine (table 2). The positive result was found in a 50-year-old man with a saccular aneurysm in the bifurcation of the right MCA (originating at the upper branch), detected during the etiology of an ischemic infarct in that vascular territory. The patient presented no focal neurological signs (motor, sensory, or visual deficits) prior to the procedure. SEPs from both the median and tibial nerves were monitored. MEPs from the contralateral upper and lower limbs (biceps, extensor digitorum, short thumb abductor, TA, and AH) were monitored as well as MEPs from the ipsilateral limbs (short thumb abductor and right $\mathrm{AH}$ ) to provide control values. The purpose of the PT was to determine the function of the upper M2 branch of the right MCA, which originated at the neck of the aneurysm and appeared to be thrombosed. $40 \mathrm{mg}$ lidocaine was injected into the tip of a microcatheter attached to the bifurcation of the right MCA. One minute after the injection, we observed a slight decrease in MEP amplitude in the left side of the body. The morphology of MEP also changed and became less polyphasic. Three minutes later, MEPs completely disappeared on the left side of the body. After this, they progressively regained their baseline value over a period of $19 \mathrm{~min}$ (fig. 1). The test was considered positive and neuroradiologists proceeded to embolize the aneurysm, while sparing the artery in question. We detected no pathologically significant changes in the parameters that were monitored during the procedure. The patient presented no neurological focal signs after extubation. No false negative results were detected in any of the other PTs.

Representative Cases of IOM Events

They occurred in 3 of the 15 procedures (20\%; table 3 ).

Patient 8

A 60-year-old male was diagnosed with a left frontal-opercular AVM (Spetzler-Martin score of 2) after suffering a left frontal-parietal hematoma. The sequelae were mild motor aphasia and minimal claudication of the right hand. We monitored and observed the reproducible responses from the SEPs in both the median and tibial nerves and from the MEPs on the right side of the body (APB, extensor digitorum, tibialis, and $\mathrm{AH}$ ). We could not detect any 


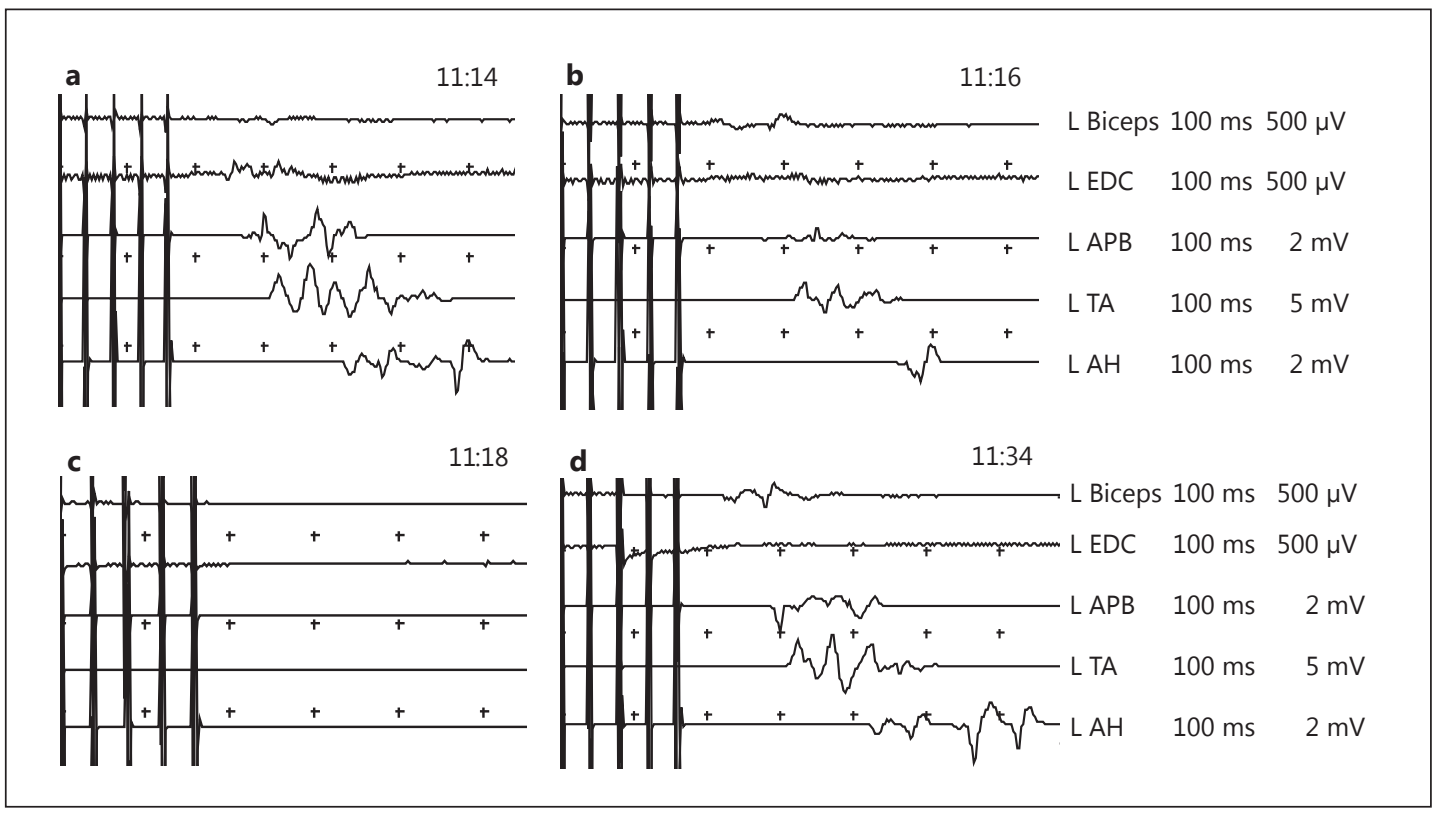

Fig. 1. Positive PT in a 50-year-old man diagnosed with a saccular aneurysm in the bifurcation of the right MCA, originating at the upper branch. a Baseline traces corresponding to the TES MEP of the left upper and lower limb muscles before injecting $40 \mathrm{mg}$ lidocaine at 11:15. b A mild decrease of the left APB, TA, and AH MEPs 1 min after the injection. c Complete loss of the left MEPs 3 min after the lidocaine injection. $\mathbf{d}$ MEP recovery until reaching baseline value 19 min after the lidocaine injection. $\mathrm{L}=\mathrm{Left}$; EDC = extensor digitorum communi.

Table 3. IOM events, type and duration, angiographic findings, interventions undertaken and outcome

\begin{tabular}{|c|c|c|c|c|c|c|}
\hline $\begin{array}{l}\text { Pa- } \\
\text { tient } \\
\text { No. }\end{array}$ & Pathology & $\begin{array}{l}\text { Endovascular } \\
\text { procedure/ } \\
\text { material }\end{array}$ & $\begin{array}{l}\text { IOM } \\
\text { methodology }\end{array}$ & $\begin{array}{l}\text { IOM } \\
\text { events } \\
\text { (type and duration) }\end{array}$ & $\begin{array}{l}\text { Angiographic } \\
\text { findings and } \\
\text { interventions }\end{array}$ & $\begin{array}{l}\text { Outcome ( } 48 \mathrm{~h} \\
\text { after endovascular } \\
\text { procedure) }\end{array}$ \\
\hline 8 & $\begin{array}{l}\text { Fronto- } \\
\text { opercular } \\
\text { AVM (left) }\end{array}$ & $\begin{array}{l}\text { Embolization/ } \\
\text { Onyx }\end{array}$ & $\begin{array}{l}\text { SEPs } \\
\text { MEPs } \\
\text { CoMEPs } \\
(\text { CTHY)* } \\
\text { PT }(L+A, 2 \times)-\end{array}$ & $\begin{array}{l}\downarrow>90 \% \text { MEP amplitude, extensor digitorum } \\
\text { communi (right) } \\
\downarrow 50 \% \text { SEP amplitude, right median nerve } \\
(14: 45-14: 51 \text {, end procedure) }\end{array}$ & $\begin{array}{l}\text { Contrast extravasation } \\
\text { Endovascular protamine injection } \\
\text { Endovascular embolization }\end{array}$ & $\begin{array}{l}\text { Fronto-temporal } \\
\text { hematoma } \\
\text { Motor aphasia and } \\
\text { moderate right } \\
\text { hemiparesia and } \\
\text { hemihypoesthesia }\end{array}$ \\
\hline 9 & $\begin{array}{l}\text { Frontal } \\
\text { AVM } \\
\text { (right) }\end{array}$ & $\begin{array}{l}\text { Embolization/ } \\
\text { Onyx }\end{array}$ & $\begin{array}{l}\text { SEPs } \\
\text { MEPs }\end{array}$ & $\begin{array}{l}\downarrow 80 \% \text { MEP amplitude, left AH }(14: 20-14: 30) \\
\text { No changes in bilateral median and tibial SEPs }\end{array}$ & $\begin{array}{l}\text { No angiographic findings } \\
\text { Stop embolization }\end{array}$ & $\begin{array}{l}\text { No neurological } \\
\text { deficits }\end{array}$ \\
\hline 3 & $\begin{array}{l}\text { Spinal cord } \\
\text { AVM } \\
(\mathrm{C} 6-\mathrm{C} 7)\end{array}$ & $\begin{array}{l}\text { Embolization/ } \\
\text { Onyx }\end{array}$ & $\begin{array}{l}\text { SEPs+MEPs } \\
\text { PT }(L, 2 \times)\end{array}$ & $\begin{array}{l}\downarrow 90 \% \text { MEP amplitude, left APB and biceps, } \\
\text { right APB and bilateral TA } \\
(12: 37 \rightarrow 12: 55) \\
\text { No changes in bilateral median and tibial SEPs }\end{array}$ & $\begin{array}{l}\text { No angiographic findings } \\
\text { Stop embolization }\end{array}$ & $\begin{array}{l}\text { No neurological } \\
\text { deficits }\end{array}$ \\
\hline
\end{tabular}

observable LLR to the CoMEP at the right CTHY muscle. Following placement of a microcatheter in the frontal-opercular branch of the left MCA up to the malformation nidus, we conducted 2 PTs by first injecting amobarbital followed by lidocaine. The results were negative.

The neuroradiologists then injected Onyx through the same microcatheter. One of the control angiograms taken during embolization revealed a contrast leak suggesting an active 


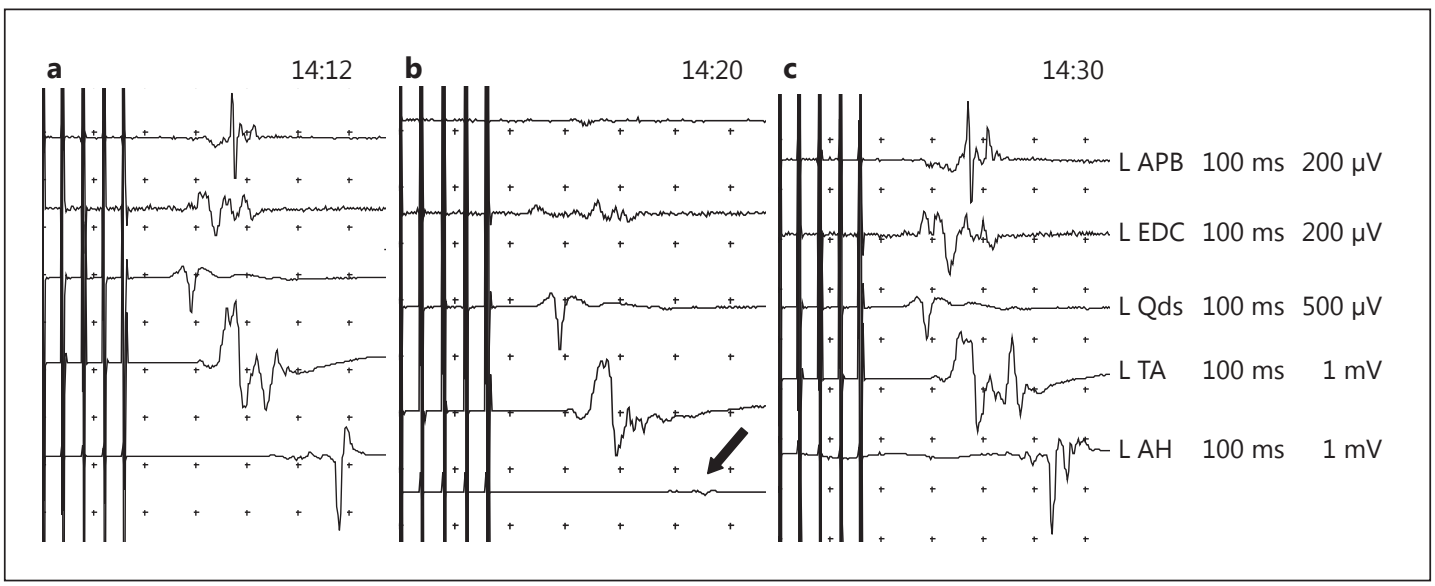

Fig. 2. Patient 9. Reversible MEP deterioration in a 38-year-old man diagnosed with a right frontal parasagittal AVM based on partial motor seizures in the left leg. a Baseline traces corresponding to the TES MEP of the left upper and lower limb muscles during a second Onyx injection. b Focal change restricted to a decrease in MEP amplitude of $>90 \%$ in the left AH muscle (black arrow). c After 10 min, embolization was terminated, and the MEP returned to its baseline level with no increase in the stimulation threshold. $\mathrm{L}=\mathrm{Left}$; EDC $=\mathrm{ex}-$ tensor digitorum communi; Qds = quadriceps.

bleed. The administration of protamine stopped the bleeding. As no pathologically significant changes were detected in the monitored parameters during this incident, the neuroradiologists continued with the procedure. The central sulcal branch of the left MCA was microcatherized.

After 2 PTs with amobarbital and lidocaine produced negative results, the doctors began embolization using Onyx. The subsequent angiography revealed a new contrast extravasation along the rest of the AVM. The neuroradiologists tried to stop the bleeding immediately by an endovascular approach and decided to stop the attempt after 6 min when an IOM event occurred (a 50\% decrease in SEP amplitude at the right median nerve, with a decrease of $>90 \%$ in MEP amplitude at the right extensor digitorum). Rotational angiography with XperCT revealed a subarachnoid hemorrhage in the interpeduncular cistern and a lobar hematoma in the left prefrontal area that was surgically removed.

\section{Patient 9}

A 38-year-old male was diagnosed with a right frontal parasagittal AVM (Spetzler-Martin score of 3) based on partial motor seizures in the left leg with no secondary neurological deficit. Studies were performed to record the SEPs in both the median and tibial nerves and the MEPs on the left side of the body (APB, extensor digitorum, quadriceps, TA, and AH). The MEPs were measured on the right side to provide control values (APB and AH). After a second Onyx embolization procedure performed through a branch of the right pericallosal artery, we observed a focal change restricted to a decrease in the MEP amplitude of $>90 \%$ in the left AH muscle. The MEPs were registered continuously from this moment onward. Some degree of fluctuation in the APB and extensor digitorum communi amplitude was detected without reaching a significant pathological level (fig. 2). The MEPs exhibit considerable trial-to-trial amplitude and morphological variability. This was attributed to fluctuating lower motor neuron background facilitation from the upper motor neuron, propriospinal, and sensory transmitters such as norepinephrine and serotonin that powerfully affect excitability [30, 31]. 
There were no significant incidents in the rest of the parameters monitored, including the bilateral tibial and median nerve SEPs as well as the ipsilateral MEPs. We ruled out technical errors as a cause of the incident and notified the neuroradiologist. Embolization with Onyx was terminated, and the patient's hemodynamic condition was optimized, even though the likelihood of a systemic change was low due to the stability of both the ipsilateral SEPs and MEPs. After $10 \mathrm{~min}$, we determined that the AH MEP amplitude had returned to its baseline level with no increase in the stimulation threshold. Our interpretation was that this change, which was focal and resolved rapidly once the procedure was terminated, may have been caused by a focal mass effect or local edema due to venous hypertension secondary to the deposition of Onyx. This could be supported by the observation that there were no incidents during the first injection performed with the tip of the microcatheter placed in the same position, the lack of evidence of Onyx reflux to distal vessels, and the fact that the AVM drained into an ectatic superficial cortical vein.

A pure focal mesial ischemia could be the cause behind this IOM event. Such focal changes are typical during endovascular procedures where superselective catheterization of small vessels takes place. Another explanation for the transient MEP change could be a focal seizure activity with Todd's paralysis. Unfortunately, no scalp EEG could be recorded in order to ascertain this hypothesis, because of technical limitations of the IOM equipment employed.

\section{Patient 3}

A 22-year-old female was diagnosed with a right cervical AVM (C6-C7) after complaining of right cervicobrachialgia and sensory disturbances in the right C7-C8 dermatome. Prior to the 5 th embolization session, there were no neurological deficits. Her baseline data included SEPs from both the median and tibial nerves and MEPs from both biceps, APB, and TA that could be reproduced and monitored. After microcatheterizing the branch of the thyrocervical-scapular trunk that fed the AVM, the doctors performed 2 PTs with lidocaine. The test results were negative, and the doctors began the Onyx embolization procedure. Thirty minutes after starting the procedure, the MEPs in the left APB and biceps disappeared almost completely. There was a significant decrease in amplitude in the right APB and in both TA. The neuroradiologist was informed about the situation, and the procedure was aborted. As the stimulus intensity was gradually increased to $180 \mathrm{~V}$ above baseline, we observed a progressive recovery of the affected MEPs, which reached their initial level after $20 \mathrm{~min}$ (fig. 3). The return of the MEP with increasing stimulus intensity could represent a threshold warning criterion reaching or exceeding a predefined limit above the baseline. In addition, the bilateral median and tibial SEPs did not show any significant change simultaneously with the MEPs, making a systemic or technical effect as the explanation of the IOM event unlikely.

\section{IOM Events and Clinical Prognosis}

Abnormal significant changes arose during monitoring in 3 of the 15 procedures included. In patients 3 and 9, these changes could be reversed through specific actions (immediately aborting the procedure, checking potentially harmful mechanisms related to the endovascular procedure, and optimizing the patients' hemodynamic and systemic conditions), resulting in no neurological deficits after the procedures. In patient 8 , the persistent IOM event was associated with a lobar hematoma; postoperatively, the patient suffered from presented moderate aphasia and hemiparesis.

No new neurological deficits were found after the procedures in patients 5, 11, and 12 regarding the preexisting deficits associated with the underlying diseases (table 3). Table 4 shows the clinical outcome, assessed by means of the modified Rankin Scale score, 3 months after the endovascular procedures. 


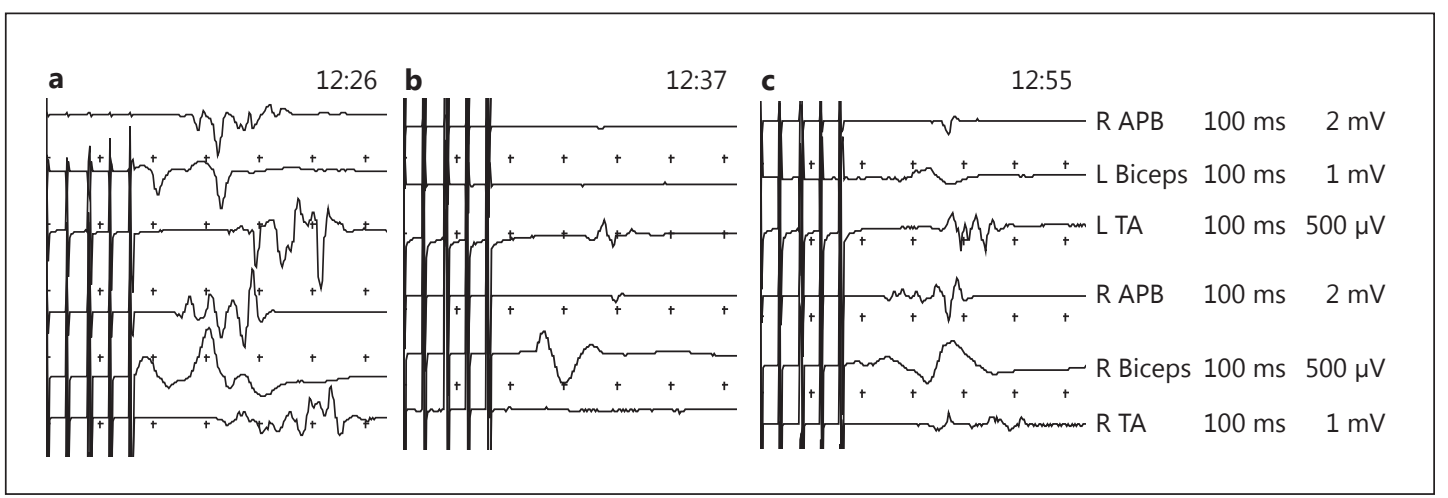

Fig. 3. Patient 3. Reversible MEP deterioration in a 22-year-old woman diagnosed with a right cervical AVM (C6-C7). a The TES MEPs at about 20 min into the Onyx embolization. $\mathbf{b}$ The MEPs in the left APB and biceps disappeared almost completely. There was a significant decrease in amplitude in the right APB and both TA. The neuroradiologist was informed about the situation, and the procedure was aborted. c As the stimulus intensity was gradually increased to $180 \mathrm{~V}$ above baseline, we observed a progressive recovery of the affected MEPs, which reached their initial level after $20 \mathrm{~min} . \mathrm{L}=\mathrm{Left}$; $\mathrm{R}=$ right.

\section{Discussion}

This study reports our experience with implementing evoked potential monitoring during the endovascular treatment of central neurovascular pathologies in patients under general anesthesia. In total, 12 patients and 15 procedures involving both spinal cord and brain lesions were monitored. Multimodality IOM methodology (SEPs, MEPs, CoMEPs, and flash-VEPs) showed significant IOM events in 3 of 15 procedures (20\%). Twelve pharmacological PTs were performed, but only $1(8.7 \%)$ was positive. Taken together, our findings show that IOM can provide a continuous near real-time assessment of the functional integrity of eloquent areas of the central nervous system during endovascular procedures when patients are under general anesthesia. This methodology enables an early detection of neurological damage and this allows us to undertake specific action, intended to correct the underlying pathogenic mechanism, preventing irreversible deficits. Furthermore, PTs let us specifically identify the vessels that feed vascular malformations.

Of note, in patient 8 , the IOM event occurred 6 min after contrast extravasation. It may be considered that during this time, monitoring was false negative. We hypothesize that the initial contrast leakage did not modify the SEP and MEP until the extent of bleeding caused brain injury, a fact that did not occur after the first transient extravasation in the same patient. This limitation should be acknowledged when arterial ruptures are detected in the angiogram. However, the present data reinforce the value of IOM in preventing ischemic complications in endovascular procedures. Experimental and clinical data indicate that the SEPs provide a reasonable estimate of the functional state of brain areas during incomplete ischemia [32, 33]. Indeed, SEP abolition is considered as the upper threshold of the state defined as ischemic penumbra, where tissue is hypoperfused but not irreversibly damaged [34].

Reports about the use of IOM during neuroendovascular procedures are characterized by their heterogeneity. Regarding the topography of a lesion, some studies only include spinal cord vascular lesions $[2,8]$, whereas others are focused in brain pathology [9, 10]. From a neurophysiological point of view, the lack of consensus is more pronounced. In spinal cord pathology, Niimi et al. [8] combined SEPs, MEPs, and PTs simultaneously in patients under general anesthesia. In brain lesions, the variability is even higher, not only regarding the IOM 
Table 4. IOM events and clinical outcome

\begin{tabular}{|c|c|c|c|c|}
\hline \multirow{2}{*}{$\begin{array}{l}\mathrm{Pa}- \\
\text { tient } \\
\text { No. }\end{array}$} & \multirow[t]{2}{*}{ Pathology } & \multirow[t]{2}{*}{ IOM events } & \multicolumn{2}{|l|}{ Outcome } \\
\hline & & & $\begin{array}{l}48 \mathrm{~h} \text { after endovascular } \\
\text { procedure }\end{array}$ & $\begin{array}{l}\text { modified Rankin Scale score } \\
\text { after } 3 \text { months }\end{array}$ \\
\hline 1 & $\begin{array}{l}\text { Spinal cord } \\
\text { AVM }(\mathrm{C} 1-\mathrm{C} 2)\end{array}$ & None & No neurological deficits & mRS 0 \\
\hline 2 & $\begin{array}{l}\text { Vertebral } \\
\text { hemangioma (T5) }\end{array}$ & None & No neurological deficits & $\begin{array}{l}\text { mRS } 3 \text { (epidural thoracic } \\
\text { hematoma } 1 \text { month after the } \\
\text { procedure) }\end{array}$ \\
\hline 3 & $\begin{array}{l}\text { Spinal cord AVM } \\
\text { (C6-C7) }\end{array}$ & $\begin{array}{l}\text { None } \\
\downarrow 90 \% \text { MEP amplitude, left APB } \\
\text { and biceps, right APB and bilateral TA } \\
\text { No changes in bilateral median and } \\
\text { tibial SEPs }\end{array}$ & $\begin{array}{l}\text { No neurological deficits } \\
\text { No neurological deficits }\end{array}$ & $\begin{array}{l}\text { mRS } 0 \\
\text { mRS } 0\end{array}$ \\
\hline 4 & MCA aneurysm (right) & None & No neurological deficits & mRS 0 \\
\hline 5 & ICA aneurysm (right) & None & No new neurological deficits & mRS 1 \\
\hline 6 & MCA aneurysm (right) & None & No neurological deficits & mRS 0 \\
\hline 7 & $\begin{array}{l}\text { Basilar artery } \\
\text { (trunk) aneurysm }\end{array}$ & None & No neurological deficits & mRS 0 \\
\hline 8 & $\begin{array}{l}\text { Fronto-opercular } \\
\text { AVM (left) }\end{array}$ & $\begin{array}{l}\downarrow>90 \% \text { MEP amplitude, right } \\
\text { extensor digitorum communi } \\
\downarrow 50 \% \text { SEP amplitude, right median } \\
\text { nerve }\end{array}$ & $\begin{array}{l}\text { Fronto-temporal hematoma } \\
\text { Motor aphasia and moderate } \\
\text { right hemiparesia and } \\
\text { hemihypoesthesia }\end{array}$ & $\begin{array}{l}\text { mRS } 2 \\
\text { Slight disability; unable to } \\
\text { carry out all activities as } \\
\text { previously, but able to look } \\
\text { after own affairs without } \\
\text { assistance }\end{array}$ \\
\hline 9 & Frontal AVM (right) & $\begin{array}{l}\downarrow 80 \% \text { MEP amplitude, left AH } \\
\text { for } 10 \text { min } \\
\text { None } \\
\text { None }\end{array}$ & $\begin{array}{l}\text { No neurological deficits } \\
\text { No neurological deficits } \\
\text { Repeated focal motor seizures } \\
\text { with Todd's paresis: left lower } \\
\text { limb plegia after } 23 \mathrm{~h} \text { of } \\
\text { orotracheal intubation } \\
\text { (recovered after } 48 \mathrm{~h} \text { ) }\end{array}$ & mRS 0 \\
\hline 10 & Occipital AVM (left) & None & No new neurological deficits & $\begin{array}{l}\text { mRS } 1 \text { (blurred vision after } \\
\text { resective surgery) }\end{array}$ \\
\hline 11 & $\begin{array}{l}\text { Cerebellar } \\
\text { (vermian) AVM }\end{array}$ & None & $\begin{array}{l}\text { No new neurological deficits } \\
\text { (previous cerebellar ataxia) }\end{array}$ & mRS 1 \\
\hline 12 & Frontal AVM (left) & None & $\begin{array}{l}\text { No new neurological deficits } \\
\text { (previous mild aphasia) }\end{array}$ & mRS 1 \\
\hline
\end{tabular}

mRS = Modified Rankin Scale score

methodology but also the type of anesthesia. Liu et al. [24] reported their experience with neurophysiological monitoring during the endovascular therapy of aneurysms using SEPs, brainstem auditory-evoked response, and EEG in patients under general anesthesia. Rauch et al. [35] used SEP monitoring during the endovascular treatment of brain AVMs in awake patients, whereas Sala et al. [10] employed both SEPs and MEPs in patients under general anesthesia. Other studies performed PTs without any kind of neurophysiological tests in awake patients [36, 37]. 
The IOM setting has to be planned individually according to the lesion's topography. Thus, it would include SEPs, MEPs, CoMEPs, brainstem auditory-evoked responses, VEPs, and scalp EEG, according to the eloquent areas in risk. Unfortunately, there are few reports where this multimodal IOM approach has been employed $[8,18]$. We would like to emphasize the critical value of MEP monitoring when motor areas and tracts are in danger, since multiple reports point to the unreliability of SEPs alone in detecting injury to the motor pathways $[5,38]$.

Although the IOM methodology applied in the present study is in agreement with previous methodological approaches, some neurophysiological techniques, such as brainstem auditory-evoked response and scalp EEG, could not be performed simultaneously in some cases because of technique limitations of the IOM equipment. Other specific limitations of IOM in interventional neuroradiology have to be taken into account. First of all, both MEPs and VEPs require TES and transcranial electrical recording, respectively. As a result, there will be some loss of specificity in patients with brain injury, especially cortical lesions. Regarding MEPs, the electrical stimulus may depolarize the corticospinal tract at the subcortical level and fail to detect functional changes rostrally in the motor cortex. Using C1/C2 as stimulation sites, along with lower intensities and the lowest possible number of pulse trains, minimizes the risk of direct subcortical activation. While using this method, we have detected no false negative results, meaning postprocedure motor deficits that were not preceded by pathologically significant changes in MEPs. D-wave recording from the cervical epidural space in cases of cortical lesions (corticospinal MEPs) could help to overcome the previous limitation. It assesses the functional status of the pyramidal tract's rapid conduction system and provides data about the patient's postoperative functional motor prognosis in intramedullary as well as brain lesions [29, 39-41]. These data could be really useful when making decisions balancing the risk/benefit ratio between achieving a complete AVM embolization and a patient's short- and long-term motor status. Although D-wave monitoring is standardized in cases of intramedullary spinal cord lesions, the technical difficulty when using the method for the endovascular treatment of brain lesions is not to be totally overlooked. In cases of spinal cord pathology, experiences were first published by Konrad et al. [42] in animal models and subsequently by Haan et al. [43] for thoracic-abdominal aorta aneurysms. They describe myogenic MEPs as being more sensitive for an early detection of spinal ischemia than MEPs recorded at the epidural level. At the same time, loss of specificity might be anticipated for VEPs that are recorded transcranially in lesions that may impair cortical visual areas. However, in a series of 100 patients (27\% with cortical brain lesions), Sasaki et al. [11] demonstrated an optimal correlation between their results and the postoperative clinical prognosis. There were no significant postsurgical visual deficits in cases that did not show a decrease in VEP amplitude of $>50 \%$ compared to baseline values.

On the other hand, interpreting PTs in brain disease is a complex matter. Apart from the limitations previously identified as being inherent to transcranial stimulation, alarm criteria are not the same as those for spinal cord lesions (a decrease in SEP amplitude of $>50 \%$ and/ or a disappearance of MEPs). Due to the complexity of brain vascularization and considering that a larger percentage of grey matter is at risk, a total lack of response from MEPs would be unspecific, although very sensitive, as a cutoff point. In their pilot study, Sala et al. [10] reported on 21 interventions to correct AVMs that potentially compromised sensorimotor brain areas. They performed 49 embolization procedures through feeding arteries that had first undergone PTs with lidocaine with negative results. After the procedures, 3 patients developed mild and transient sensorimotor deficits [10]. These results suggest that a negative result from a lidocaine test might guarantee an absence of subsequent persistent sensorimotor deficits even in the brain. According to cumulative experience, decreases in SEP and MEP amplitude of $\geq 50 \%$ seem to be significant. 
Other important considerations are whether the changes are focal or generalized, the speed with which they appear, whether they occur after amobarbital or lidocaine treatment, and whether they involve motor or sensory deficits. In any case, these data must be shared with the neuroradiologist and assessed in a joint work session to determine whether they are significantly based on the lesion's vascular architecture. These data also help us to decide whether the risk/benefit ratio of attempting embolization is feasible given the probabilities of complete or partial closure of the AVM. While following this method, we have detected no false negative results for any of the 8 PTs in our patients with cerebrovascular abnormalities. In our study, only 1 PT with lidocaine was positive. It was considered true positive because no intervention was undertaken in the vascular territory where the PT was performed, and the patient awoke without neurological deficits. Nonetheless, false positive results are difficult to ascertain in IOM because, for ethical reasons, the patients could not be exposed to the risk of neurological deficits to rule out whether a positive test is a true or false positive result.

Monitoring language and cognitive function is also a difficult matter when the patient is under general anesthesia. In this case, it is possible to use LLR to CoMEPs in the CTHY muscle $[25,44]$. One limitation of this approach is that it only may reflect the functional status of motor areas for language articulation, while overlooking other vitally important areas (supplementary motor area, Wernicke's area, and associated fibers). An alternative approach is to keep the patient awake using superficial sedation and performing a PT using a microcatheter placed at the site chosen for embolization. If the test result is negative, i.e. if a neuropsychological assessment reveals no language disorders, the procedure can then be undertaken with the patient under general anesthesia. Nevertheless, this approach requires the patient's full cooperation, and any involuntary movements by the patient may interfere with the procedure.

It could be expect that implementing IOM may lead to an increase in the length of endovascular procedures. However, in our experience, a skilled IOM professional is able to perform a montage of the electrodes as well as the recording of baseline traces while the anesthesiologist and nurses are placing vascular and urinary catheters, without causing a delay in the procedure. A cost-benefit analysis regarding the implementation of IOM in spinal surgeries conclude that IOM remained cost-saving even when the neurological complication rate from surgery exceeded $0.3 \%(\mathrm{p}<0.001)$ and the prevention rate after IOM alert was $>14.2 \%(\mathrm{p}=$ 0.02) [45]. To our knowledge, no cost-benefit analysis has been published regarding the implementation of IOM during neuroendovascular procedures.

In conclusion, IOM may provide continuous real-time data about the functional status of eloquent areas and pathways of the central nervous system in patients under general anesthesia. All these factors make endovascular procedures safer, and in doing so, they could minimize the risk of persistent secondary neurological deficits.

\section{Acknowledgements}

This study was supported by the Río Hortega scholarship granted by the Instituto de Salud Carlos III (Spanish Ministry of Economy and Competitiveness). We would like to thank Drs. Isabel Fernández Conejero, Sedat Ulkatan, and Enrica Fava for their teachings and support. We also thank Ms. Rosa García and Ms. Cristina Hidalgo for always being willing to help. Additionally, we thank the Spanish Society of Neurology's Research Operations Office (OISEN) for their assistance in translating the manuscript.

\section{Disclosure Statement}

All authors declare no sponsorship or funding arrangements related to their research as well as no conflicts of interest. 
Martinez Piñeiro et al.: Implementation of Intraoperative Neurophysiological

Monitoring during Endovascular Procedures in the Central Nervous System

\section{References}

1 Niimi Y, Deletis V, Berenstein A: Neurophysiological monitoring during spinal endovascular procedures; in Nuwer MR (ed): Intraoperative Monitoring of Neural Function - Handbook of Clinical Neurophysiology. Amsterdam, Elsevier, 2008, p 651.

$\longrightarrow 2$ Berenstein A, Young W, Ransohoff J, Benjamin V, Merkin H: Somatosensory evoked potentials during spinal angiography and therapeutic transvascular embolization. J Neurosurg 1984;60:777-785.

3 Hacke W: Evoked potentials monitoring in interventional neuroradiology; in Desmedt JE (ed): Neuromonitoring in Surgery. Amsterdam, Elsevier, 1989, pp 331-342.

-4 Ginsburg HH, Shetter AG, Raudzens PA: Postoperative paraplegia with preserved intraoperative somatosensory evoked potentials. Case report. J Neurosurg 1985;63:296-300.

5 Jones SJ, Buonamassa S, Crockard HA: Two cases of quadriparesis following anterior cervical discectomy, with normal perioperative somatosensory-evoked potentials. J Neurol Neurosurg Psychiatry 2003;74:273-276.

6 Szelényi A, Deletis V: Motor evoked potentials. J Neurosurg 2004;101:563-564.

-7 Szelényi A, Kothbauer KF, Deletis V: Transcranial electric stimulation for intraoperative motor evoked potential monitoring: stimulation parameters and electrode montages. Clin Neurophysiol 2007;118:15861595.

8 Niimi Y, Sala F, Deletis V, Setton A, de Camargo AB, Berenstein A: Neurophysiologic monitoring and pharmacologic provocative testing embolization of spinal cord arteriovenous malformations. AJNR Am J Neuroradiol 2004;25:1131-1134.

-9 Paulsen RD, Steinberg GK, Norbash AM, Marcellus ML, Lopez JR, Marks MP: Embolization of rolandic cortex arteriovenous malformations. Neurosurgery 1999;44:479-486.

10 Sala F, Lanteri P, Beltramello A, et al: Intraoperative neurophysiological monitoring and provocative tests during embolization of brain arteriovenous malformations in motor areas: a preliminary experience on 21 procedures (abstract). Interv Neuroradiol 2005;11:179-180.

11 Sasaki T, Itakura T, Suzuki K, et al: Intraoperative monitoring of visual evoked potential: introduction of a clinically useful method. J Neurosurg 2010;112:273-284.

12 Deletis V, Engler G: Somatosensory evoked potentials for spinal cord monitoring; in Bridwell KH, DeWald RL (eds): The Textbook of Spinal Surgery. Philadelphia, Lippincott-Raven, 1997, pp 85-92.

13 Holderfer RN, Sadlier R, Russell MJ: Predicted current densities in the brain during transcranial electrical stimulation. Clin Neurophysiol 2006;117:1388-1397.

14 MacDonald DB, Stigsby B: Use of D waves in intraoperative monitoring; in Proceedings of the Symposium on Intraoperative Neurophysiology (Ljubljana Institute of Clinical Neurophysiology). October 17, 2003. www. kclj.si/ikn/Dejavnosti/FAGA/2003/INVI2003.HTM (accessed November 12, 2003).

15 Szelényi A, Kothbauer KF, Deletis V: Transcranial electric stimulation for intraoperative motor evoked potential monitoring: stimulation parameters and electrode montages. Clin Neurophysiol 2007;118:15861595.

16 Penfield W, Boldrey E : Somatic motor and sensory representation in the cerebral cortex of man as studied by electrical stimulation. Brain 1937;60:389-433.

17 Cohen LG, Hallet M: Noninvasive mapping of human motor cortex. Neurology 1988;38:904-909.

18 Sala F, Beltramello A, Gerosa M: Neuroprotective role of neurophysiological monitoring during endovascular procedures in the brain and spinal cord. Neurophysiol Clin 2007;37:415-421.

19 McDonald DB, Al Zayed Z, Al Saddigi A: Four limb muscle motor evoked potential and optimized somatosensory evoked potential monitoring with decussation assessment: results in 206 thoracolumbar spine surgeries. Eur Spine J 2007;16:S171-S187.

20 Calancie B, Molano MR: Alarm criteria for motor-evoked potentials: what's wrong with the 'presence-orabsence' approach? Spine (Phila Pa 1976) 2008;3:406-414.

21 Calancie B, Harris W, Broton JG, Alexeva N, Green BA: 'Threshold-level' multipulse transcranial electrical stimulation of motor cortex for intraoperative monitoring of spinal motor tracks: description of method and comparison to somatosensory evoked potential monitoring. J Neurosurg 1998;88:457-471.

-22 McDonald DB, Skinner S, Shils J, Yingling C: Intraoperative motor evoked potential monitoring - a position statement by the American Society of Neurophysiological Monitoring. Clin Neurophysiol 2013;124:22912316.

-23 Szelenyi A, Hattingen E, Weidauer S, Seifert V, Ziemann U: Intraoperative motor evoked potential alteration in intracranial tumor surgery and its relation to signal alteration in postoperative magnetic resonance imaging. Neurosurgery 2010;67:302-313.

24 Liu AY, Lopez JR, Do HM, Steinberg GK, Cockroft K, Marks MP: Neurophysiological monitoring in the endovascular therapy of aneurysms. AJNR Am J Neuroradiol 2003;24:1520-1527.

25 Deletis V, Fernandez-Conejero I, Ulkatan S, Rogic M, Carbo E, Hiltzik D: Methodology for intra-operative recording of the corticobulbar motor evoked potentials from cricothyroid muscles. Clin Neurophysiol 2011; 122:1883-1889.

26 Hirano M, Ohala J: Use of hooked-wire electrodes for electromyography of the intrinsic laryngeal muscles. J Speech Hear Res 1969;12:362-373. 
Martinez Piñeiro et al.: Implementation of Intraoperative Neurophysiological

27 Niimi Y, Sala F, Deletis V, Setton A, Bueno de Camargo A, Berenstein A: Neurophysiologic monitoring and pharmacologic provocative testing for embolization of spinal cord arteriovenous malformations. AJNR Am J Neuroradiol 2004;25:1131-1138.

28 Tanaka K, Yamasaki M: Blocking of cortical inhibitory synapses by intravenous lidocaine. Nature 1966;209: 207-208.

29 Sala F, Palandri G, Basso E, et al: Motor evoked potential monitoring improves outcome after surgery for intramedullary spinal cord tumors: a historical control study. Neurosurgery 2006;58:1129-1143.

-30 Amassian VE: Animal and human motor system neurophysiology related to intraoperative monitoring, in Deletis V, Shils J (eds): Neurophysiology in Neurosurgery - A Modern Intraoperative Approach. San Diego, Academic Press, 2002.

-31 Heckman CJ, Mottram C, Quinlan K, Theiss R, Schuster J: Motoneuron excitability: the importance of neuromodulatory inputs. Clin Neurophysiol 2009;120:2040-2054.

-32 Graf R, Kataoka K, Rosner G, Heiss W-D: Cortical deafferentation in cat focal ischemia: disturbance and recovery of sensory functions in cortical areas with different degrees of cerebral blood flow reduction. J Cereb Blood Flow Metab 1986;6:566-573.

-33 Matsuyima N, Koehler RC, Traystman RJ: Consistency of cerebral blood flow and evoked potential alterations with reversible focal ischemia in cats. Stroke 1990;21:908-916.

-34 Astrup J, Siesjo BK, Symon L: Thresholds in cerebral ischemia - the cerebral penumbra. Stroke 1981;12:723725.

-35 Rauch RA, Vinuela F, Dion J, et al: Preembolization functional evaluation in brain arteriovenous malformations: the ability of superselective Amytal test to predict neurologic dysfunction before embolization. AJNR Am J Neuroradiol 1992;13:309-314.

-36 Feliciano CE, de León-Berra R, Hernández-Gaitán MS, Torres HM, Creagh 0, Rodríguez-Mercado R: Provocative test with propofol: experience in patients with cerebral arteriovenous malformations who underwent neuroendovascular procedures. AJNR Am J Neuroradiol 2010;31:470-475.

37 Wang Q, Chen G, Gu Y, Song D: Provocative tests and parent artery occlusion in the endovascular treatment of distal middle cerebral artery pseudoaneurysms. J Clin Neurosci 2011;18:1741-1743.

-38 Lesser RP, Raudzens PA, Luders H, et al: Postoperative neurological deficits may occur despite unchanged intraoperative somatosensory evoked potentials. Ann Neurol 1986;19:22-25.

-39 Kothbauer K, Deletis V, Epstein FJ: Motor evoked potential monitoring for intramedullary spinal cord tumor surgery: correlation of clinical and neurophysiological data in a series of 100 consecutive procedures. Neurosurg Focus 1998;4:e1-e9.

40 Fujiki M, Furukawa Y, Kamida T, et al: Intraoperative corticomuscular potentials for evaluation of motor function: a comparison with corticospinal D and I waves. J Neurosurg 2006;104:85-92.

41 Deletis V, Sala F: Intraoperative neurophysiological monitoring of the spinal cord during spinal cord and spine surgery: a review focus on the corticospinal tracts. Clin Neurophysiol 2008;119:248-264.

-42 Konrad PE, Tacker WA, Levy WJ, et al: Motor evoked potentials in the dog: effects of global ischemia on spinal cord and peripheral nerve signals. Neurosurgery 1987;20:117-124.

43 Haan P, Kalkman CJ, Jacobs MJ: Spinal cord monitoring with myogenic motor evoked potentials: early detection of spinal cord ischemia as an integral part of spinal cord protective strategies during thoracoabdominal aneurysm surgery. Semin Thorac Cardiovasc Surg 1998;10:19-24.

44 Deletis V, Rogic M, Fernández-Conejero I, Gabarrós A, Jeroncic A: Neurophysiologic markers in laryngeal muscles indicate functional anatomy of laryngeal primary motor cortex and premotor cortex in the caudal opercular part of inferior frontal gyrus. Clin Neurophysiol 2014;125:1912-1922.

45 Ney JP, Van der Goes DN, Watanabe JH: Cost-benefit analysis: intraoperative neurophysiological monitoring in spinal surgeries. J Clin Neurophysiol 2013;30:280-286. 